\title{
Aplicações da distração osteogênica na região dentofacial: o estado da arte*
}

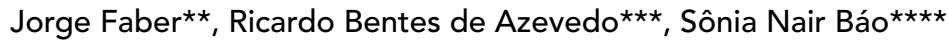

Resumo

A distração osteogênica é uma forma de engenharia de tecidos na qual a separação gradual de margens ósseas cirurgicamente seccionadas resulta na geração de novo osso, cujo processo geral de regeneração é similar à ossificação intramembranosa. A técnica ganhou muitas aplicações na região dentofacial que variam da movimentação dentária a avanços da mandíbula ou da face média. Esse artigo revisa a literatura sobre o assunto com o objetivo de proporcionar ao ortodontista e ao cirurgião bucomaxilofacial uma abordagem atualizada das características biológicas e clínicas dessa técnica.

Palavras-chave: Distração osteogênica. Distração maxilo-mandibular. Distração dentária. Distração periodontal. Revisão.

\section{INTRODUÇÃO}

A distração osteogênica (DO) é uma forma de engenharia de tecidos in vivo na qual a separação gradual de margens ósseas, cirurgicamente seccionadas, resulta na geração de novo osso.

A regeneração tecidual produzida pela DO foi largamente utilizada na Ortopedia para regenerar ossos longos após o encurtamento de um membro inferior por trauma, osteomielite ou outra condição. Um limitado sucesso era encontrado na formação de novo tecido ósseo e, em especial, na união dos fragmentos ósseos distraídos. Isso acarretava uma alta incidência de complicações e, como conseqüência, a maioria dos ortopedistas focava sua atenção no encurtamento dos membros de dimensões normais ou no uso de próteses externas para compensar as diferenças de comprimento dos membros ${ }^{12}$.

Os trabalhos de Ilizarov ${ }^{27,28,29}$ trouxeram soluções para os principais problemas enfrentados com a DO em ossos longos. Esses trabalhos permitiram que uma grande variedade de aplicações fosse desenvolvida para a área dentofacial, variando de avanços da face média ${ }^{8}$ ao movimento dentário ${ }^{42}$.

Esse artigo revisa a literatura sobre o assunto com o objetivo de proporcionar ao ortodontista e ao cirurgião bucomaxilofacial uma abordagem atualizada das características biológicas e clínicas dessa técnica na região dentofacial.

\footnotetext{
* Trabalho extraído de parte da tese do primeiro autor, realizada como requisito parcial para a obtenção do título de Doutor em Biologia Animal pelo Programa de Pós-Graduação em Biologia Animal do Instituto de Ciências Biológicas da Universidade de Brasília.

** Doutor em Biologia Animal - Morfologia pela Universidade de Brasília. Mestre em Ortodontia pela Universidade Federal do Rio de Janeiro.

*** Doutor em Biologia Celular e Tecidual pela Universidade de São Paulo - São Paulo. Professor Adjunto do Departamento de GenéDoutor em Biologia Celular e Tecidual pela Universidade de São Paulo - São Pa
tica e Morfologia, Instituto de Ciências Biológicas, Universidade de Brasília.

**** Doutora em Ciências pela Universidade Federal do Rio de Janeiro. Professora Titular do Departamento de Biologia Celular, Instituto de Ciências Biológicas, Universidade de Brasília.
} 
PRINCÍPIOS BIOLÓGICOS DA DISTRAÇÃO OSTEOGÊNICA

Fatores necessários para a regeneração óssea através da distração osteogênica

A preservação do suprimento sangüíneo da região a ser distraída é o primeiro fator para a realização da DO. A regeneração tecidual produzida por essa técnica depende da manutenção de uma adequada vascularização da área quando a distração dos fragmentos ósseos é feita ${ }^{2,28}$. Foram desenvolvidas, então, diversas técnicas cirúrgicas para a secção óssea e todas visam preservar o suprimento sangüíneo do periósteo, endósteo e medula óssea para otimizar a indução da regeneração. As principais técnicas são: 1) a osteotomia que separa completamente os dois fragmentos a serem distraídos, incluindo o osso esponjoso; 2) a corticotomia que preserva a integridade dos espaços medulares e osso esponjoso; 3) a osteotomia que se estende sobre parte do osso esponjoso seguida pela indução de uma fratura orientada na porção restante e; 4) a osteoclase fechada, onde uma fratura é realizada com auxílio de instrumentos de forma a não romper o periósteo (Fig. 1). Adicionalmente, se um adequado cuidado for tomado com a manipulação dos tecidos moles, o aporte sangüíneo da área distraída se assemelhará ao de uma fratura por trauma ${ }^{2}$, onde o reparo é favorecido pela preservação dos tecidos moles adjacentes.

A separação através da osteoclase já se mostrou superior às outras técnicas no que diz respeito à quantidade de tecido ósseo regenerado ${ }^{27}$, porém é uma técnica de difícil controle e limitada aplicação, em especial, em ossos não tubulares e de estrutura mais frágil como os ossos faciais. Dessa forma, osteotomias que separam completamente os fragmentos têm sido usadas com freqüência tanto experimentalmente quanto clinicamente ${ }^{6,35,47,62} \mathrm{e}$ trazem bons resultados desde que haja uma cuidadosa manipulação do periósteo ${ }^{38}$.

Durante a cirurgia para separação dos fragmentos o distrator deve ser fixado e sua instala- ção precede a osteotomia ${ }^{9,59,62}$. A estabilidade dos fragmentos a serem tracionados e do distrator é a segunda condição para a realização da $\mathrm{DO}^{27}$. Quanto mais rígido é o conjunto "fragmentos ósseos/distrator", mais eficaz é a regeneração óssea e menor é a probabilidade de se desenvolver uma pseudo-artrose ${ }^{27}$.

Após a fixação do distrator e realização das osteotomias para permitir a movimentação dos fragmentos a serem distraídos, um período de latência pode ser empregado. A necessidade ${ }^{29,66}$ ou não ${ }^{6,62}$ desse intervalo é motivo de controvérsia. Muitos estudos em animais e em pacientes utilizaram esse período de inatividade do distrator por até cerca de 7 dias $^{26,29,38,45,51,59,66}$, tendo sido atribuído a ele um aumento na quantidade de regeneração ${ }^{29,66}$ Contudo, uma revisão de 3.278 casos de aplicações crânio-faciais da DO não encontrou evidências que sustentassem a necessidade do período de inatividade do distrator ${ }^{48}$. Aparentemente, à medida que o cirurgião adquire experiência clínica com o uso da DO, ele tende a diminuir ou eliminar o período de latência ${ }^{6,48}$.

Ao se imaginar diferentes tipos de aplicações clínicas da DO, é possível que a diminuição ou eliminação do período de latência possa ser algo benéfico ou não. Exemplificando, o alongamento mandibular em crianças com deformidades dentofaciais é favorecido por uma diminuição do tempo de tratamento ${ }^{6}$. Nesses pacientes não é fácil obter uma boa colaboração ${ }^{7}$ e quanto mais rápido o tratamento for realizado, melhor. Mas após a colocação de um distrator intrabucal, quando edema e dor estão presentes no pós-operatório, a adoção de um período de latência pode beneficiar o paciente por proporcionar mais conforto devido à menor manipulação da região.

A despeito do uso ou não de um período de latência, depois de realizada a cirurgia para desunião do osso a ser tratado, o distrator precisa ser ativado em adequadas taxa e freqüência. Nesse momento se inicia a distração óssea propriamente dita e a adesão a um protocolo de ativação do 


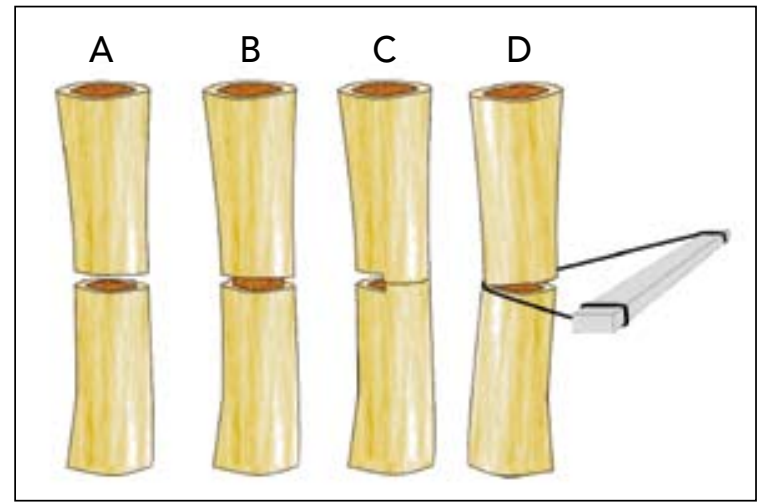

FIGURA 1 - 0 esquema representa os métodos de separação mais utilizados em ossos tubulares. A) osteotomia para separação completa dos fragmentos através da incisão do periósteo. B) corticotomia que preserva praticamente intactos o osso esponjoso e a medula óssea. C) osteotomia não completa do osso; a separação é terminada através de uma fratura. D) osteoclase fechada, onde um fio de aço espesso circunda o periósteo e é tracionado para provocar uma fratura.

aparelho compõe o terceiro e último fator para o sucesso da $\mathrm{DO}^{29}$. A situação clínica ideal seria que a distração fosse realizada rapidamente (taxas de muitos milímetros por dia) e com freqüências baixas (uma vez ao dia ou menos) pois isso seria o mais cômodo para o paciente. Ainda não existem evidências que fundamentem a adoção de um único protocolo e é até possível que diferentes protocolos surjam como a melhor alternativa de tratamento para os diferentes ossos e em diversas idades. Praticamente não há discordâncias a respeito da necessidade diária de ativação ${ }^{12,13,31,47}$, mas muitas variações existem nas taxa e freqüência empregadas $6,29,35,45,59$, que variam de $1,0 \mathrm{~mm}$ ao dia em 4 incrementos de $0,25 \mathrm{~mm}^{29,48}$, a mais de 1,0 mm diariamente em uma única ativação ${ }^{48}$. Entretanto, ganhos diários maiores que $1,0 \mathrm{~mm}$ tenderam a diminuir o estímulo osteogênico ${ }^{48,60}$.

Após o término da distração, um período de contenção é utilizado para que o tecido regenerado adquira a resistência bioelástica necessária para resistir às forças de recidiva. Um período de seis semanas se mostrou adequado em diferentes modelos experimentais ${ }^{49,57}$ e períodos com amplitude entre 2,4 a 10 semanas já foram utilizados após a DO mandibular em pacientes $s^{6,26,31,45}$.
Histopatologia da regeneração através da distração osteogênica

A região da regeneração pela DO possui uma microanatomia característica (Fig. 2). Nos primeiros dias de distração, uma zona fibrosa constituída de colágeno $32,34,38,59,62$ é formada na região central da distração e é delimitada por colunas ósseas paralelas com muitos osteoblastos ativos ${ }^{29,34,38,59,62,66}$. Todo este conjunto é arranjado no sentido do tracionamento. Ilhas de tecido cartilaginoso po$\mathrm{dem}^{3,13,34,62,66}$ ou não $\mathrm{o}^{20}$ ser encontradas.

A mineralização da região ocorre das margens ósseas para a zona central fibrosa ${ }^{1}$ e a formação de uma ponte óssea unindo essas margens acontece em um prazo que varia em decorrência da quantidade de distração realizada, podendo demorar de duas semanas a um mês ${ }^{6,13,48}$. Ao final do tracionamento, as colunas ósseas se unem e o tecido ósseo passa por um intenso processo de remodelação ${ }^{27-29,35,62}$.

O modo básico de regeneração óssea durante a distração é similar à ossificação intramembrano$\mathrm{sa}^{32}$, que é um processo rigidamente regulado para produzir, em última análise, osso lamelar remodelado, proveniente da calcificação dos feixes de

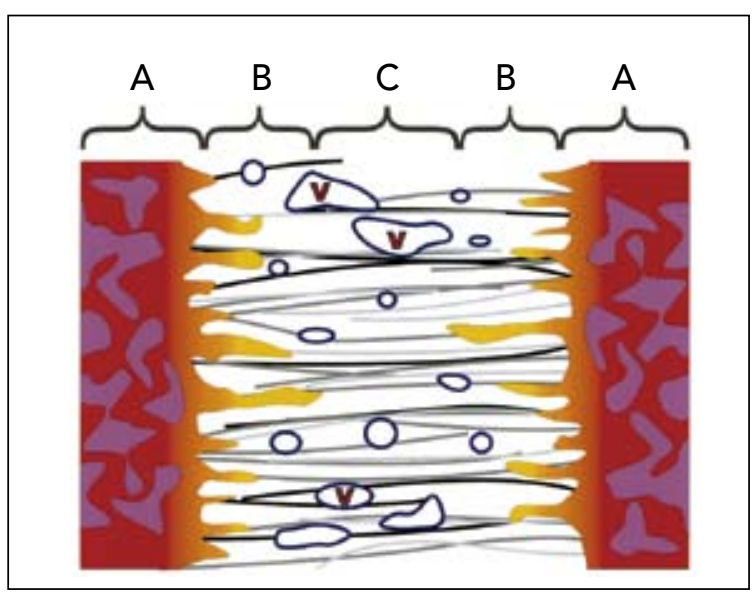

FIGURA 2 - Esquema demostrando a microanatomia da região de regeneração durante o período de distração. A) margem do osso que recebeu a osteotomia. B) região de neoformação óssea onde as colunas de tecido ósseo neoformado (em amarelo) se estendem em direção à zona central fibrosa. C) zona central fibrosa composta por muitos feixes de fibras colágenas do tipo I, fibroblastos, e células mesenquimais indiferenciadas (células não representadas no esquema). Muitos vasos sangüíneos estão presentes na região de regeneração (v). 
fibras de colágeno do tipo $\mathrm{I}^{47}$. Na matriz da distração há pouco colágeno do tipo II, característico de um calo cartilaginoso, e o colágeno do tipo I, presente no tecido ósseo, compõe quase que exclusivamente as fibrilas colágenas sintetizadas ${ }^{32}$.

Os mecanismos que coordenam a formação óssea durante a DO não são completamente conhecidos, mas uma regulação por força mecânica parece ser crítica para a neoformação tecidual ${ }^{63}$. A cascata de transdução de sinal mediada pelas integrinas é o principal mecanismo pelo qual a transdução do estímulo mecânico ocorre nas células e parece estar relacionado à regulação da formação óssea durante a $\mathrm{DO}^{63}$. Além disso, um número crescente de citocinas tem sido relacionado com a regulação da síntese óssea. Durante a distração, uma intensa produção de TGF - $ß_{1}$ mRNA (ácido ribonucleico mensageiro da proteína fator de crescimento do tecido beta um) e da proteína TGF - $\beta_{1}$ (fator de crescimento do tecido beta um) leva a uma angiogênese e coincide com a migração, diferenciação e síntese da matriz extra-celular por parte dos osteoblastos ${ }^{47}$. Uma elevada expressão de colágeno do tipo IV ocorre na membrana basal dos vasos sangüíneos neoformados e laminina está presente de forma difusa na matriz em ossificação ${ }^{20}$. As BMPs (proteínas morfogenéticas do osso) 2, 4 e 7 são também muito expressas no tecido conjuntivo no mesmo período ${ }^{4}$.

Em seguida à sua produção, a matriz extracelular é mineralizada. A regulação da mineralização é feita pela osteocalcina, cuja liberação coincide temporalmente com a deposição de cálcio na matriz ${ }^{47}$.

As alterações dimensionais do osso distraído levam a simultâneas expansões no periósteo, músculos, tecido adiposo e pele ${ }^{53}$. Os músculos que possuem uma orientação paralela ao eixo de distração tem seu volume aumentado através de regeneração compensatória e hipertrofia ${ }^{18}$.

\section{Aplicações da distração osteogênica na área den- tofacial}

Distração osteogênica para avanço mandibular

A estruturação da técnica da DO feita por
Ilizarov $^{27,}$ 28, 29 possibilitou sua aplicação em diferentes ossos do corpo, inclusive nos da região dentofacial, cujos primeiros empregos focaram o alongamento da mandíbula ${ }^{6,35,45}$.

Diferentes modelos experimentais têm sido usados, como ratos ${ }^{47,54}$, ovelhas $s^{33,34,62}$, minipor$\cos ^{49}$, cães ${ }^{11,18,20,35,36,57}$ e coelhos ${ }^{59}$ para auxiliar a compreensão dos mecanismos clínicos e biológicos relacionados à DO. A maioria dos trabalhos utilizou distratores ancorados ao osso, mas dispositivos presos aos dentes ${ }^{49}$ e a implantes osteointegrados ${ }^{56}$ também foram testados e se mostraram eficazes.

O procedimento tem sido indicado principalmente para pacientes que apresentam síndromes ou deformidades dentofaciais muito severas, tais como síndromes de Treacher-Collins e Pierre Robin, microssomia hemifacial e anquilose da articulação têmporo-mandibular6,10,14,26,45,55. $\mathrm{Na}$ maior parte desses pacientes, a designação dessa opção de tratamento se dá menos pelos impactos psico-sociais e funcionais de mastigação e fala, mas principalmente em decorrência da presença de apnéia obstrutiva do sono ou da dependência de traqueostomia causada pela grande deficiência mandibular ${ }^{6,10}$.

A DO para alongamento mandibular também já foi realizada em pacientes que apresentam micrognatia $^{52}$ e para a reconstrução da articulação têmporo-mandibular ${ }^{61}$. Ainda que essas condutas sejam eficazes, elas devem ser indicadas com cautela no tratamento de deformidades dentofaciais que podem ser corrigidas através de métodos cujos prognósticos são bem estabelecidos e requerem um único tempo cirúrgico ${ }^{15}$, pois, ainda que os resultados dos tratamentos possam ser similares, a morbidade da DO é maior e esta ainda pode resultar em cicatrizes na face se distratores extrabucais forem aplicados ${ }^{6,52}$.

As técnicas cirúrgicas descritas variam pouco e podem empregar tanto distratores intrabucais quanto extrabucais ${ }^{6,26,45}$ e o resultado final da distração parece ser estável ${ }^{46}$. Uma das abordagens cirúrgicas mais usuais emprega uma osteotomia contínua sobre toda a superfície lateral da mandíbula. 
A secção completa do osso é realizada apenas nas regiões mais inferior e superior do corte. A separação restante é feita através de uma fratura para evitar danos ao feixe vásculo-nervoso no interior do canal mandibular ${ }^{6,14,26,45}$, como pode ser visto na figura 3. A orientação dessa osteotomia deve ser planejada de acordo com o sentido desejado da regeneração, como está representado na figura $3 \mathrm{~A}$ e B. O restante da separação é feito através de uma fratura provocada pelo distrator ${ }^{14}$, intra-operatoriamente, ou por um cinzel usado como alavanca rotatória ${ }^{14,45}$. A implantação de um enxerto ósseo na região da osteotomia, combinado com a DO, já foi relatada com o intuito de prover um avanço imediato da mandíbula para melhorar o quadro respiratório do paciente ${ }^{10}$.

Alterações de sensibilidade do nervo alveolar inferior, em decorrência da DO mandibular, não são freqüentes ${ }^{26,52}$, mas podem ocorrer. Elas parecem estar mais associadas à técnica da osteotomia do que ao estiramento do nervo ${ }^{44}$.

Distração osteogênica para expansão mandibular

A expansão mandibular através da DO foi descrita pela primeira vez em $1990^{23}$ e essa abordagem já se mostrou eficaz, embora estudos com acompanhamento a longo prazo não estejam disponíveis. Sua principal indicação é a deficiência mandibular transversal ${ }^{3}$, freqüente em pacientes com deformidades dentofaciais como a microssomia hemifacial ou a síndrome da microglossiaadactilia. Nesses casos o paciente pode apresentar um estreitamento excessivo do arco dentário e ósseo, e dentes ausentes podem ser encontrados ${ }^{3}$.

Indivíduos que apresentam um apinhamento severo no arco mandibular, com freqüência, são submetidos a tratamento ortodôntico com a exodontia de quatro pré-molares para a solução da discrepância dentária negativa ${ }^{37}$. A DO para expansão mandibular tem sido indicada como uma outra alternativa de tratamento para esses pacientes. Assim, um aumento no perímetro do arco dentário é conseguido através de uma expansão mandibular conjugada a um tratamento ortodôntico e extrações dentárias não são realizadas ${ }^{24,65}$. No entanto, a decisão por essa modalidade de tratamento parece se justificar em poucos casos, pois o tratamento com exodontias é menos mórbido, traz bons resultados estéticos e funcionais ${ }^{42}$, já foi avaliado a longo prazo ${ }^{42,43}$ e possui um custo bastante menor. Além do mais, quando o paciente possui antes do tratamento uma relação transversal adequada dos dentes posteriores, é indispensável a implementação de uma expansão maxilar convencional em adolescentes ou cirurgicamente assistida em adultos ${ }^{65}$.

O procedimento cirúrgico consiste no levantamento de um retalho mucoperiósteo no vestíbulo mandibular, com mínima desinserção dos tecidos na crista óssea do rebordo alveolar para que o suprimento sangüíneo desta área não seja afetado ${ }^{3}$. A proeminência das raízes dos incisivos é visualizada e uma osteotomia nesta linha imaginária interincisal é feita com uma serra recíproca, abaixo do ápice dos incisivos, até seccionar completamente a sínfise mentoniana ${ }^{3,65}$. Após o afastamento do retalho superiormente, uma corticotomia é

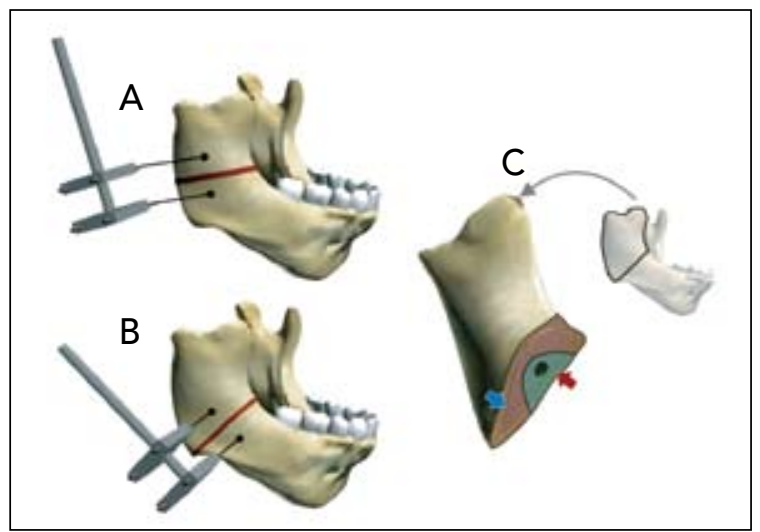

FIGURA 3 - Esse esquema reproduz a mandíbula de um hipotético paciente com microssomia hemifacial com o lado direito afetado. A orientação da osteotomia tem íntima relação com a direção do alongamento planejado. A, B) diferentes posicionamentos de osteotomias (em vermelho) e distratores para se obter, respectivamente, vetores de crescimento mais vertical e horizontal. C) fragmento proximal após ter sido girado para permitir uma visão ânterolateral. A seta azul aponta a área que é seccionada através de uma serra ou broca. 0 restante da separação mandibular é feito através de uma fratura da área destacada pela seta vermelha. Essa conduta visa manter a integridade do feixe vásculo-nervoso presente nessa área. 
estendida sobre a superfície óssea até a crista e é completada com um cinzel delicado de forma a separar a mandíbula na linha média ${ }^{3,24,65}$. O distrator usado pode tanto ser ancorado ao osso da região mentoniana quanto aos dentes por um expansor tipo Hyrax ${ }^{24,65}$. Efeitos deletérios sobre as raízes e periodonto não foram observados ao se utilizar distratores presos aos dentes ${ }^{49}$.

Com o tratamento de distração mandibular na linha média os côndilos sofrem um giro sobre um eixo vertical ${ }^{25}$ levando a alterações nas articulações têmporo-mandibulares (ATMs). Essa movimentação leva a mudanças morfológicas não transitórias ${ }^{25,58}$ nas camadas fibrosa, cartilaginosa e na interface osso/cartilagem dos côndilos ${ }^{25}$. Esse quadro sugere que a distração transversal da mandíbula seja usada com cautela pois pode ter efeitos adversos sobre as $\mathrm{ATMs}^{58}$.

Distração osteogênica para avanço do complexo dentomaxilar

Duas técnicas cirúrgicas principais são utilizadas para o avanço do complexo dentomaxilar combinado com a DO: as osteotomias de Le Fort I e Le Fort III.

As cirurgias que empregam osteotomias de Le Fort III são indicadas em pacientes com graves deficiências da porção superior da face ${ }^{8}$. Esse tipo de deformidade é rotineiro em portadores das síndromes de Crouzon e Apert. Apesar dos avanços na técnica cirúrgica para a realização das osteotomias e na anestesia pediátrica, o procedimento ainda é complexo e com uma significativa morbidade ${ }^{8,22}$. A técnica cirúrgica para realização das osteotomias não difere daquela realizada para um avanço convencional com uso de fixação interna rígida e se dá através de um acesso coronal ${ }^{8}$.

A resistência dos tecidos moles ao tracionamento do fragmento de Le Fort III limita a menos de dez milímetros a quantidade de movimento anterior possível através da mobilização, avanço e fixação com miniplacas e parafusos ${ }^{8,22}$. Quando a DO é empregada, pela natureza gradual e regene- radora do procedimento, avanços de até $30 \mathrm{~mm}$ foram relatados ${ }^{8}$.

Quando a cirurgia para a distração envolve osteotomias de Le Fort I, o avanço do fragmento dentoósseo pode ser feito por distratores fixados ao osso ou com forças geradas por elásticos presos a uma máscara facial ${ }^{39}$. A quantidade de movimentação do fragmento conseguida pelos distratores é bastante superior àquela possível com a máscara ${ }^{39}$.

Distração osteogênica para o aumento do rebordo alveolar com finalidade implantodôntica

Uma aplicação cada vez mais freqüente da DO na área dentofacial é o aumento da quantidade de osso do rebordo alveolar edentado maxilar ou mandibular para a colocação de implantes osteointegrados. Diversos métodos de distração já foram empregados e variam de parafusos distratores propriamente $\operatorname{ditos}^{7,21}$, a implantes osteointegrados gradualmente rosqueados para promover a regeneração óssea ${ }^{19,56}$. A metodologia aplicada para a distração alveolar se assemelha àquela existente para outros ossos. As vantagens ao se empregar essas técnicas em detrimento de métodos convencionais como o enxerto ósseo ${ }^{5,50,55}$ são evitar uma cirurgia na área doadora e acelerar a colocação do implante.

As duas alternativas de DO para o osso alveolar têm eficácia demostrada em séries de relatos de $\operatorname{casos}^{19,21,30,64}$. Todavia, não existem trabalhos que comparem as técnicas entre si, ou mesmo as compare com técnicas convencionais de enxerto ósseo para que se possa afirmar a superioridade clínica de uma frente à outra.

Distração osteogênica do osso alveolar e dente para movimentação dentária

Liou e Huang ${ }^{41}$ aplicaram um modelo inovador de DO ao periodonto com a finalidade de acelerar a movimentação dentária ortodôntica. O método foi denominado de distração dentária. A técnica objetiva atingir uma movimentação dentária rápida para o espaço de extração após pequenas corticotomias no septo interdental (Fig. 4). 


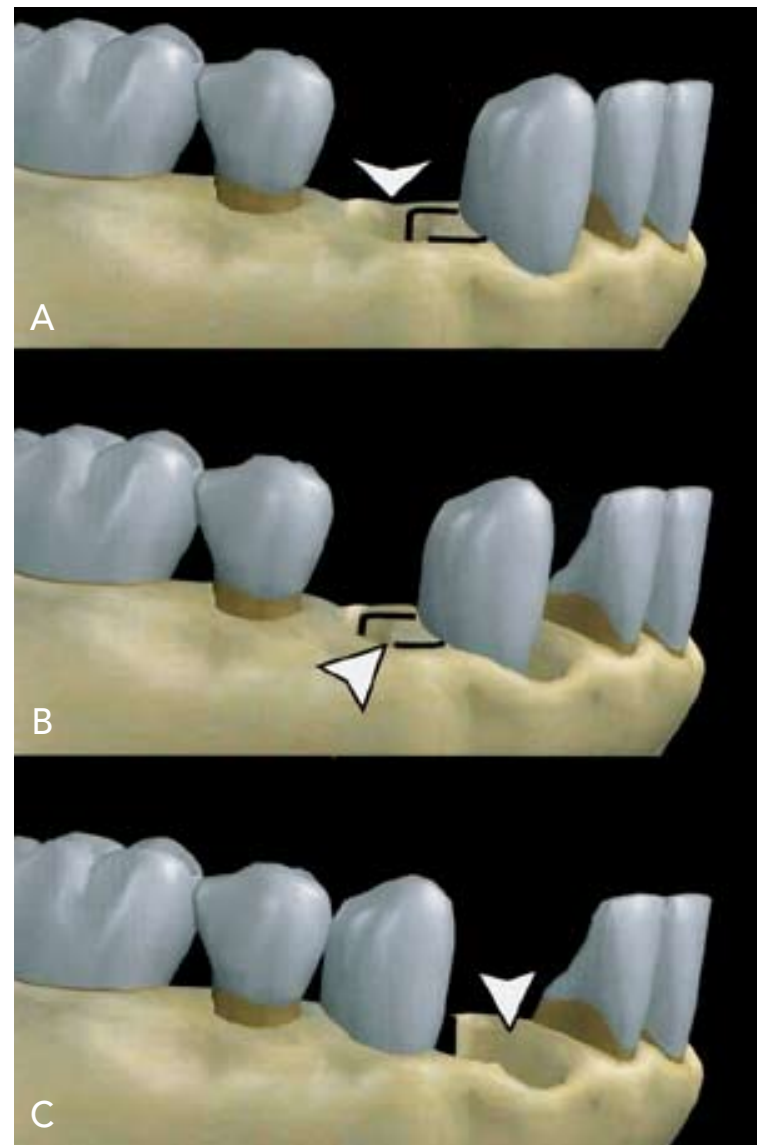

FIGURA 4 - Representação da distração dentária aplicada ao canino. Nesse esquema 0 aparelho ortodôntico e o distrator não foram incorporados para facilitar a compreensão do procedimento. Em $\mathbf{A}$ a seta indica 0 alvéolo após a exodontia do primeiro pré-molar inferior direito e, à sua direita, podem ser visualizadas as corticotomias no septo interdental. Em B está realçado pela seta o septo interdental deslocado com o dente após pequena movimentação do conjunto dente-septo. Em C, a movimentação está terminada e a seta salienta o espaço do ligamento periodontal aumentado. Toda a movimentação dura cerca de 3 semanas.

Os cortes são realizados com uma broca cirúrgica no momento em que a extração dentária é feita e não tocam a superfície radicular do dente a ser movimentado. Todo o fechamento do espaço de extração dura cerca de 3 semanas, diminuindo em muitos meses o tempo de tratamento. O ligamento periodontal estirado em muitos milímetros exibiu sinais radiográficos de reparação.

A distração dentária também foi empregada para diminuir as dimensões de uma fenda palatina pela movimentação do complexo dento-ósseo através da fenda, em direção à outra margem óssea ${ }^{40}$.

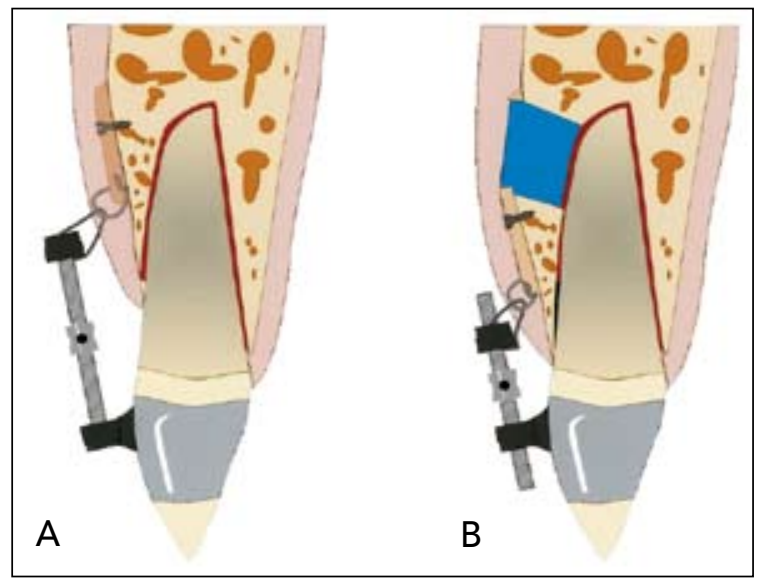

FIGURA 5 - Distração periodontal para regeneração do periodonto. A) periodonto reduzido com distrator em posição; B) ao final do procedimento, a distração periodontal promove uma regeneração dos tecidos periodontais.

Distração osteogênica para regeneração periodontal (Distração Periodontal)

Recentemente, Faber et al. ${ }^{16,17}$ desenvolveram uma metodologia de distração osteogênica para a regeneração do periodonto. $\mathrm{O}$ procedimento, denominado distração periodontal, objetiva realizar o tracionamento gradual de parte do periodonto sobre uma região onde um defeito periodontal foi experimentalmente criado (Fig. 5).

Os resultados obtidos em cães sugerem que essa técnica possui uma capacidade regeneradora maior que alternativas existentes de regeneração tecidual guiada e ela poderá, talvez, abrir uma nova perspectiva no tratamento de pacientes jovens e adultos que possuem um periodonto reduzido em decorrência de trauma ou da doença periodontal inflamatória aguda ou crônica. Essa nova perspectiva acoplará o tratamento ortodôntico à terapia periodontal com o intuito de proporcionar uma regeneração dos tecidos periodontais ao mesmo tempo em que os dentes são movimentados para se obter melhores oclusão e estética, trazendo assim mais saúde e bem estar para os pacientes.

\section{CONCLUSÃO}

Os mecanismos através dos quais a regeneração tecidual ocorre durante a distração osteogêni- 
ca são parcialmente compreendidos. Esta técnica congrega um conjunto de procedimentos cujas aplicações se encontram em expansão na área dentofacial, onde iniciou pelo alongamento da mandíbula, e hoje é utilizada até para induzir a movimentação dentária ortodôntica ou regenerar o periodonto. Um conhecimento mais profundo de suas aplicações por ortodontistas e cirurgiões bucomaxilofaciais, possivelmente, permitirá a dis- seminação da técnica e a obtenção de melhores resultados de tratamento para certas condições.

\section{AGRADECIMENTOS}

Os autores agradecem à Dra. Patrícia Medeiros Berto por sua criteriosa revisão desse artigo.

\section{Dentofacial applications of distraction osteogenesis: The state of the art}

\section{Abstract}

Distraction osteogenesis is a tissue engineering technique in which the gradual separation of surgically sectioned bone edges results in the generation of new bone. The basic regeneration process is similar to intramembranous ossification. A great number of applications has been found for it in the dentofacial complex, ranging from tooth distraction to midface advancement. This article reviews the literature regarding distraction osteogenesis with the aim of providing the orthodontist and oral surgeon an updated approach to the clinical and biological aspects of this technique.

Key words: Distraction osteogenesis. Maxillo-mandibular distraction. Tooth distraction. Periodontal distraction. Review.

\section{REFERÊNCIAS}

1. ARONSON, J. et al. Preliminary studies of mineralization during distraction osteogenesis. Clin Orthop, Philadelphia, v. 250, p. 43-49, Jan. 1990.

2. ARONSON, J. Temporal and spatial increases in blood flow during distraction osteogenesis. Clin Orthop, Philadelphia, v. 301, p. 124-131, Apr. 1994.

3. BELL, W.H. et al. Distraction osteogenesis to widen the mandible. Br J Oral Maxillofac Surg, Edinburgh, v. 35, no. 1, p. 11-19, Feb. 1997.

4. CAMPISI, P. et al. Expression of bone morphogenetic proteins during mandibular distraction osteogenesis. Plast Reconstr Surg, Hagerstown, v. 111, no. 1, p. 201-210, Jan. 2003.

5. CAPLANIS, N. et al. Effect of allogeneic, freeze-dried, demineralized bone matrix on guided bone regeneration in supra-alveolar peri-implant defects in dogs. Int J Oral Maxillofac Implants, Lombard, v. 12, no. 5, p. 634-642, Sept../Oct. 1997.

6. CARLS, F. R.; SAILER, H. F. Seven years clinical experience with mandibular distraction in children. J Craniomaxillofac Surg, Edinburgh, v. 26, no. 4, p. 197-208, Aug. 1998.

7. CHIN, M.; TOTH, B. A. Distraction osteogenesis in maxillofacial surgery using internal devices: review of five cases. J Oral Maxillofac Surg, Philadelphia, v. 54, no. 1, p. 45-53, Jan. 1996.

8. CHIN, M.; TOTH, B. A. Le Fort III advancement with gradual distraction using internal devices. Plast Reconstr Surg, Hagerstown, v. 100 , no. 4, p. 819-830, Sept. 1997.

9. $\mathrm{CHOI}, \mathrm{I}$. H. et al. Effect of the distraction rate on the activity of the osteoblast lineage in distraction osteogenesis of rat's tibia. Immunostaining study of the proliferating cell nuclear antigen, osteocalcin, and transglutaminase C. Bull Hosp Jt Dis, New York, v. 56, no. 1, p. 34-40, 1997

10. COHEN, S. R.; SIMMS, C.; BURSTEIN, F. D. Mandibular distraction osteogenesis in the treatment of upper airway obstruction in children with craniofacial deformities. Plast Reconstr Surg, Hagersto- wn, v. 101, no. 2, p. 312-318, Feb. 1998.

11. COSTANTINO, P. D. et al. Segmental mandibular regeneration by distraction osteogenesis. An experimental study. Arch Otolaryngol Head Neck Surg, Chicago, v. 116, no. 5, p. 535-545, May 1990.

12. DE BASTIANI, G. et al. Limb lengthening by callus distraction (callotasis). J Pediatr Orthop, New York, v. 7, no. 2, p.129-134, Mar./Apr. 1987.

13. DELLOYE, C. et al. Bone regenerate formation in cortical bone during distraction lengthening. An experimental study. Clin Orthop, Philadelphia, v. 250, p. 34-42, Jan. 1990.

14. DINER, P. A. et al. Submerged intraoral device for mandibular lengthening. J Craniomaxillofac Surg, Edinburgh, v. 25, no. 3, p. 116-123, June 1997.

15. DONLON, W. C. The Bizarro world of osteodistraction. J Oral Maxillofac Surg, Philadelphia, v. 56, no. 1, p.115, Jan. 1998.

16. FABER, J. Distração periodontal: um novo método de promover a regeneração do periodonto. 2003. 96 f. Tese (Doutorado)-Universidade de Brasília, Brasília, DF, 2003.

17. FABER, J.; AZEVEDO, R. B.; BÁO, S. N. Distraction Osteogenesis May Promote Periodontal Regeneration. J Dent Res, United States, v. 84 , no. 8, p. 757-761, 2005.

18. FISHER, E. et al. Histopathologic and biochemical changes in the muscles affected by distraction osteogenesis of the mandible. Plast Reconstr Surg, Hagerstown, v. 99, no. 2, p. 366-371, Feb. 1997.

19. GAGGL, A.; SCHULTES, G.; KARCHER, H. Vertical alveolar ridge distraction with prosthetic treatable distractors: a clinical investigation. Int J Oral Maxillofac Implants, Lombard, v. 15, no. 5, p. 701-710, Sept./Oct. 2000.

20. GANEY, T. M. et al. Basement membrane of blood vessels during distraction osteogenesis. Clin Orthop, Philadelphia, v. 301, p. 132-138, Apr. 1994.

21. GARCIA, A. G. et al. Minor complications arising in alveolar distraction osteogenesis. J Oral Maxillofac Surg, Philadelphia, v. 60, no. 5, p. 496-501, May 2002.

22. GOSAIN, A. K. et al. Midface distraction following Le Fort III and monobloc osteotomies: problems and solutions. Plast Reconstr 
Surg, Hagerstown, v. 109, no. 6, p. 1797-1808, May 2002

23. GUERRERO, C. Rapid mandibular expansion. Rev Venez Ortod, Caracas, v. 48 , p. 1-2, 1990.

24. GUERRERO, C. A. et al. Mandibular widening by intraoral distraction osteogenesis. Br J Oral Maxillofac Surg, Edinburgh, v. 35, no. 6, p. 383-392, Dec. 1997.

25. HARPER, R. P. et al. Reactive changes in the temporomandibular joint after mandibular midline osteodistraction. Br J Oral Maxillofac Surg, Edinburgh, v. 35, no. 1, p. 20-25, Feb. 1997.

26. HOLLIER, L. H. et al. Mandibular growth after distraction in patients under 48 months of age. Plast Reconstr Surg, Hagerstown, v. 103, no. 5, p. 1361-1370, Apr. 1999.

27. ILIZAROV, G. A. Clinical application of the tension-stress effect for limb lengthening. Clin Orthop, Philadelphia, v. 250, p. 8-26, Jan. 1989.

28. ILIZAROV, G. A. The tension-stress effect on the genesis and growth of tissues. Part I. The influence of stability of fixation and soft-tissue preservation. Clin Orthop, Philadelphia, v. 238, p. 249-281, Jan. 1989.

29. ILIZAROV, G. A. The tension-stress effect on the genesis and growth of tissues. Part II. The influence of the rate and frequency of distraction. Clin Orthop, Philadelphia, v. 239, p. 263-285, Feb. 1989.

30. JENSEN, O. T. et al. Anterior maxillary alveolar distraction osteogenesis: a prospective 5-year clinical study. Int J Oral Maxillofac Implants, Lombard, v. 17, no. 1, p. 52-68, Jan./Feb. 2002.

31. JUENGER, T. H.; KLINGMUELLER, V.; HOWALDT, H. P. Application of ultrasound in callus distraction of the hypoplastic mandible: an additional method for the follow-up. J Craniomaxillofac Surg, Edinburgh, v. 27, no. 3, p. 160-167, June 1999.

32. KALLIO, T. J. et al. Early bone matrix formation during distraction. A biochemical study in sheep. Acta Orthop Scand, Oslo, v. 65 , no. 4, p. 467-471, Aug. 1994

33. KARAHARJU-SUVANTO, T.; KARAHARJU, E. O.; RANTA, R. Mandibular distraction. An experimental study on sheep. J Craniomaxillofac Surg, Edinburgh, v. 18, no. 6, p. 280-283, Aug. 1990

34. KARAHARJU-SUVANTO, T. et al. Distraction osteogenesis of the mandible. An experimental study on sheep. Int J Oral Maxillofac Surg, Copenhagen, v. 21, no. 2, p. 118-121, Apr. 1992.

35. KARP, N. S. et al. Bone lengthening in the craniofacial skeleton. Ann Plast Surg, Boston, v. 24, no. 3, p. 231-237, Mar. 1990.

36. KARP, N. S. et al. Membranous bone lengthening: a serial histological study. Ann Plast Surg, Boston, v. 29, no. 1, p. 2-7, July 1992

37. KOCADERELI, I. The effect of first premolar extraction on vertical dimension. Am J Orthod Dentofacial Orthop, St. Louis, v. 116, no. 1, p. 41-45, July 1999.

38. KOGIMOTO, H. et al. Bone lengthening in rabbits by callus distraction. The role of periosteum and endosteum. J Bone Joint Surg Br, London, v. 70, no. 4, p. 543-549, Aug. 1988.

39. KRIMMEL, M. et al. External distraction of the maxilla in patients with craniofacial dysplasia. J Craniofac Surg, Edinburgh, v. 12, no. 5 , p. 458-463, Sept. 2001

40. LIOU, E. J. et al. Interdental distraction osteogenesis and rapid orthodontic tooth movement: a novel approach to approximate a wide alveolar cleft or bony defect. Plast Reconstr Surg, Hagerstown, v. 105, no. 4, p. 1262-1272, Apr. 2000

41. LIOU, E. J.; HUANG, C. S. Rapid canine retraction through distraction of the periodontal ligament. Am J Orthod Dentofacial Orthop, St. Louis, v. 114, no. 4, p. 372-382, Oct. 1998.

42. LITTLE, R. M. Stability and relapse of dental arch alignment. Br J Orthod, London, v. 17, no. 3, p. 235-241, Aug. 1990.

43. LITTLE, R. M.; WALLEN, T. R.; RIEDEL, R. A. Stability and relapse of mandibular anterior alignment-first premolar extraction cases treated by traditional edgewise orthodontics. Am J Orthod, St. Louis, v. 80 , no. 4 , p. $349-365$, Oct. 1981

44. MAKAROV, M. R. et al. Evaluation of inferior alveolar nerve function during distraction osteogenesis in the dog. J Oral Maxillofac Surg, Philadelphia, v. 56, no. 12, p. 1417-1423, Dec. 1998.

45. McCARTHY, J. G. et al. Lengthening the human mandible by gradual distraction. Plast Reconstr Surg, Hagerstown, v. 89, no. 1, p. 1-8, Jan. 1992.

46. McTAVISH, J. et al. Does the sheep mandible relapse following lengthening by distraction osteogenesis? J Craniomaxillofac Surg, Edinburgh, v. 28, no. 5, p. 251-257, Oct. 2001.

47. MEHRARA, B. J. et al. Rat mandibular distraction osteogenesis: II.
Molecular analysis of transforming growth factor beta-1 and osteocalcin gene expression. Plast Reconstr Surg, Hagerstown, v. 103, no. 2, p. 536-547, Feb. 1999

48. MOFID, M. M. et al. Craniofacial distraction osteogenesis: a review of 3278 cases. Plast Reconstr Surg, Hagerstown, v. 108, no. 5, p. 1103-1114, Oct. 2001

49. NIEDERHAGEN, B. et al. Tooth-borne distraction of the mandible. An experimental study. Int J Oral Maxillofac Surg, Copenhagen, v. 28 , no. 6, p. 475-479, Dec. 1999.

50. NYSTRÖM, E.; KAHNBERG, K. E.; GUNNE, J. Bone grafts and Branemark implants in the treatment of the severely resorbed maxilla: a 2-year longitudinal study. Int J Oral Maxillofac Implants, Lombard, v. 8, no. 1, p. 45-53, 1993

51. PADWA, B. L. et al. Simultaneous maxillary and mandibular distraction osteogenesis with a semiburied device. Int J Oral Maxillofac Surg, Copenhagen, v. 28, no. 1, p. 2-8, Feb. 1999.

52. RACHMIEL, A.; LEVY, M.; LAUFER, D. Lengthening of the mandible by distraction osteogenesis: report of cases. J Oral Maxillofac Surg, Philadelphia, v. 53, no. 7, p. 838-846, July 1995.

53. ROTH, D. A. et al. A CT scan technique for quantitative volumetric assessment of the mandible after distraction osteogenesis. Plast Reconstr Surg, Hagerstown, v. 99, no. 5, p. 1237-1247, Apr. 1997.

54. ROWE, N. M. et al. Rat mandibular distraction osteogenesis: Part I. Histologic and radiographic analysis. Plast Reconstr Surg, Hagerstown, v. 102, no. 6, p. 2022-2032, Nov. 1998.

55. SATOW, S. et al. Interposed bone grafts to accommodate endosteal implants for retaining mandibular overdentures. A 1-7 year follow-up study. Int J Oral Maxillofac Surg, Copenhagen, v. 26, no. 5, p. 358-364, Oct. 1997.

56. SAWAKI, Y. et al. Mandibular lengthening by intraoral distraction using osseointegrated implants. Int J Oral Maxillofac Implants, Lombard, v. 11, no. 2, p. 186-193, Mar./Apr. 1996.

57. SMITH, S. W.; SACHDEVA, R. C.; COPE, J. B. Evaluation of the consolidation period during osteodistraction using computed tomography. Am J Orthod Dentofacial Orthop, St. Louis, v. 116, no. 3, p. 254-263, Sept. 1999.

58. STELNICKI, E. J. et al. Remodeling of the temporomandibular joint following mandibular distraction osteogenesis in the transverse dimension. Plast Reconstr Surg, Hagerstown, v. 107, no. 3, p. 647-658, Mar. 2001.

59. STEWART, K. J. et al. Mandibular distraction osteogenesis: a comparison of distraction rates in the rabbit model. J Craniomaxillofac Surg, Edinburgh, v. 26, no. 1, p. 43-49, Feb. 1998.

60. STEWART, K. J. et al. A quantitative analysis of the effect of insulin-like growth factor-1 infusion during mandibular distraction osteogenesis in rabbits. Br J Plast Surg, Edinburgh, v. 52, no. 5, p. 343-350, July 1999.

61. STUKCKI-MCCORMICK, S. U.; WINICK, R.; WINICK, A. Distraction osteogenesis for the reconstruction of the temporomandibular joint. N Y State Dent J, New York, v. 64, no. 3, p. 36-41, Mar. 1998.

62. TAVAKOLI, K. et al. The role of latency in mandibular osteodistraction. J Craniomaxillofac Surg, Edinburgh, v. 26, no. 4, p. 209-219, Aug. 1998.

63. TONG, L. et al. Focal adhesion kinase expression during mandibular distraction osteogenesis: evidence for mechanotransduction. Plast Reconstr Surg, Hagerstown, v. 111, no. 1, p. 211-222, Jan. 2003.

64. URBANI, G. Alveolar distraction before implantation: a report of five cases and a review of the literature. Int J Periodontics Restorative Dent, Chicago, v. 21, no. 6, p. 569-579, Dec. 2001.

65. WEIL, T. S.; VAN SICKELS, J. E.; PAYNE, C. J. Distraction osteogenesis for correction of transverse mandibular deficiency: a preliminary report. J Oral Maxillofac Surg, Philadelphia, v. 55, no. 9, p. 953-960, Sept. 1997.

66. WHITE, S. H.; KENWRIGHT, J. The timing of distraction of an osteotomy. J Bone Joint Surg Br, London, v. 72, no. 3, p. 356-361, May 1990.

\section{Endereço para correspondência}

Jorge Faber

SCN Q.5 bloco A sala 408 Centro Empresarial Brasília Shopping

Brasília/DF - CEP: 70.710-500

E-mail: jorgefaber@terra.com.br 